\author{
ARTIGO \\ do $\underline{\text { https://doi.org/10.22481/praxisedu.v16i40.6446 }}$
}

\title{
FORMAÇÃO PROFISSIONAL DOCENTE: PERFIL E COMPREENSÃO DE PROFESSORES DE UMA ESCOLA PÚBLICA DO RS
}

\author{
TEACHER PROFESSIONAL TRAINING: PROFILE AND UNDERSTANDING OF \\ TEACHERS OF A PUBLIC SCHOOL OF RS
}

\begin{abstract}
ENTRENAMIENTO PROFESIONAL DEL PROFESOR: PERFIL Y COMPRENSIÓN DE LOS PROFESORES DE UNA ESCUELA PUBLICA DE RS
\end{abstract}

\author{
Renata Godinho Soares \\ Universidade Federal do Pampa - Brasil
}

Jaqueline Copetti

Universidade Federal do Pampa - Brasil

\begin{abstract}
Resumo: O objetivo principal deste estudo foi de identificar o perfil e a compreensão de professores sobre formação profissional docente e a importância desta para atuação docente. Participaram da pesquisa 21 professores dos anos finais do ensino fundamental de uma escola municipal, que responderam um questionário com questões fechadas para traçar o perfil dos docentes e questões abertas para identificar a compreensão quanto a formação profissional docente e a importância sobre esta questão. Quanto ao perfil docente, a maioria são mulheres, o tempo médio de formação foi de 14 anos, com tempo médio de atuação como docente de 13 anos. Relacionada a compreensão sobre Formação Profissional Docente, os professores ampliaram esta, considerando-a não apenas como aspectos para progressão na carreira, mas também a reflexão sobre sua ação na prática em sala de aula. Os participantes consideram ser extremamente relevante manter-se atualizados e em constante formação profissional. Considera-se importante pesquisas que identifiquem as necessidades e a importância de ações formativas que os professores buscam, a fim de ofertar cursos significativos e condizentes com a realidade escolar onde estes profissionais se encontram.
\end{abstract}

Palavras chave: Curso de Formação; Ensino Fundamental; Formação Continuada; Professores.

\begin{abstract}
The main objective of this study was to identify the profile and understanding of teachers about teacher vocational training and its importance for teaching practice. The study included 21 teachers from the final years of elementary school of a municipal school, who answered a questionnaire with closed questions to profile teachers and open questions to identify the understanding of training education and the importance of this issue. Regarding the teaching profile, most of them are women, the average time of training was 14 years, with an average time of work as a teacher of 13 years. Related to the understanding of Teacher Professional Training, the teachers expanded this, considering it not only
\end{abstract}


as aspects for career progression, but also the reflection on their action in practice in the classroom. Participants consider it extremely relevant to stay up-to-date and in constant professional training. It is considered important studies that identify the needs and importance of formative actions that teachers seek, in order to offer significant courses consistent with the school reality where these professionals are.

Keywords: Training Course; Elementary School; Continuing training; Teachers.

Resumen: El objetivo principal de este estudio fue identificar el perfil y la comprensión de los profesores sobre la formación profesional del profesorado y su importancia para la práctica docente. Veintiún profesores de los últimos años de primaria de una escuela municipal participaron en el estudio, quienes respondieron un cuestionario con preguntas cerradas para rastrear el perfil de los maestros y preguntas abiertas para identificar la comprensión de la formación profesional de la enseñanza y la importancia en este tema. En cuanto al perfil docente, la mayoría de ellas son mujeres, el tiempo medio de formación fue de 14 años, con un tiempo medio de trabajo como profesora de 13 años. Relacionado con la comprensión de la Formación Profesional del Profesorado, los profesores ampliaron esto, considerándolo no sólo como aspectos para la progresión profesional, sino también la reflexión sobre su acción en la práctica en el aula. Los participantes consideran que es muy relevante mantenerse al día y en constante formación profesional. Se consideran estudios importantes que identifican las necesidades y la importancia de las acciones formativas que buscan los profesores, con el fin de ofrecer cursos significativos coherentes con la realidad escolar donde se encuentran estos profesionales.

Palabras clave: Curso de Formación; Escuela primaria; Entrenamiento continuado; Profesores.

\section{Introdução}

A formação de professores destaca-se como um tema crucial e de grande importância dentre as políticas públicas para a educação, pois os desafios apresentados à escola exigem do trabalho educativo outro patamar profissional, muito superior aos que hoje existem. Além de oferecer uma formação inicial consistente, é preciso proporcionar aos professores oportunidades de formação permanente (GOMES, 2015).

Muitos são os modelos ou propostas de formação continuada que são apresentados para os professores em diferentes níveis de ensino, em diferentes contextos sociais e em diferentes países, enfatizando cada vez mais a necessidade vital de educação permanente. Muitas dessas propostas são eficientes e eficazes quando se adaptam às necessidades dos docentes, quando são motivadoras ao ato de ensinar e ao consequente ato de aprender (ANTUNES; PLASZEWSKI, 2018).

Toda intervenção que provoca mudanças no comportamento, na informação, nos conhecimentos, na compreensão e nas atitudes dos professores em exercício é considerada como meio de formação profissional, pois a formação 
implica a aquisição de conhecimentos, atitudes e habilidades relacionadas ao campo profissional. (IMBERNÓN, 2011, p. 115).

Ao utilizar-se do termo Formação Profissional Docente para, assim, tratar da formação de professores, concorda-se com Nóvoa (2017), quando o autor relata que parece uma ideia simples, mas que define um rumo claro: a formação docente deve ter como matriz a formação para uma profissão. O autor complementa, ainda, que "a formação é fundamental para construir a profissionalidade docente, e não só para preparar os professores do ponto de vista técnico, científico ou pedagógico" (NÓVOA, 2017, p. 1131).

Assim, os avanços nas práticas e nas propostas no campo da formação de professores podem ocorrer com a superação de modelos retalhados e estanques de formação continuada atualmente rotulada como sendo pouco eficaz. Esses pacotes e discursos tendem a servir de referência para se pensar estratégias de organização de uma lógica formativa que atenda a diversidade na sua singularidade e, também, na sua generalidade (GALINDO; INFORSATO, 2016).

Nesse sentido, proporcionar uma formação que seja condizente com a realidade dos professores, corrobora com o pensamento de Nóvoa, de que a formação se constrói através de "um trabalho de reflexão crítica sobre as práticas e de (re)construção permanente de uma identidade pessoal, por isso é tão importante investir na pessoa e dar estatuto ao saber da experiência" (NÓVOA, 1992, p. 38). Tornar-se professor é transformar uma predisposição numa disposição pessoal. Assim, "precisamos de espaços e de tempos que permitam um trabalho de autoconhecimento, de autoconstrução. Precisamos de um acompanhamento, de uma reflexão sobre a profissão" (NÓVOA, 2017, p. 1121).

Com base nestas colocações, percebe-se a necessidade de pensar e estruturar cursos de formação juntamente com os professores que participarão destes, pois estes podem ser desenvolvidos na perspectiva da realidade, abordando os problemas vividos no contexto escolar ao qual pertencem (SOUZA, 2007; FONTANA; FAVERO, 2013). Concorda-se com Leitão e Alarcão (2006), quando estes afirmam que "perspectivar a formação de professores num quadro paradigmático reflexivo é criar as condições para que tal aconteça "(LEITÃO; ALARCÃO, 2006, p.67).

Formar o professor na mudança e para a mudança por meio do desenvolvimento de capacidades reflexivas em grupo, é abrir caminho para uma verdadeira autonomia profissional compartilhada, já que a profissão docente deve compartilhar o conhecimento com o contexto (IMBERNÓN, 2011, p.15). Ambos autores (Nóvoa e Imbernón) destacam a formação 
profissional docente voltada para dentro das questões vividas pelos educadores em âmbito escolar, já que as formações servem como subsídio para que os professores possam tomar decisões melhores ou resolver problemas de forma mais justa.

Com isso, utilizando-se de um curso de formação onde a primeira ação foi a investigação sobre as reais necessidades formativas dos professores, e pela importância e relevância do tema nas diferentes instâncias educacionais, o objetivo deste estudo foi de identificar o perfil e a compreensão de professores sobre formação profissional docente e a importância desta para atuação docente.

\section{Procedimentos Metodológicos}

O presente estudo caracteriza-se como uma pesquisa qualitativa, exploratória e descritiva. Pois de acordo com Gil (2010), a pesquisa exploratória busca familiarizar-se com um assunto ainda pouco conhecido ou pouco explorado. E ressalta ainda, que "[...] as pesquisas descritivas, têm como objetivo primordial a descrição das características de determinada população" (GIL, 2010, p.27).

Este artigo é um recorte de uma dissertação de mestrado, o qual foi aprovado pelo Comitê de Ética em Pesquisa da instituição oriunda. Foram sujeitos deste estudo os professores dos anos finais do ensino fundamental de uma escola pública municipal da fronteira oeste do estado do RS. Em uma reunião de apresentação do estudo, assinaram o termo de consentimento livre e esclarecido, concordando em participar de forma voluntária do mesmo 26 professores.

Os professores foram convidados a responder um questionário elaborado pelas autoras e o conteúdo do mesmo foi validado por quatro pesquisadores com grau de doutorado e ampla experiência na área a qual está centrado o estudo. O instrumento foi composto por questões fechadas que trataram do perfil dos docentes, como: idade, tempo de atuação como docente, carga horária de trabalho semanal, formação acadêmica e complementar, entre outros. Nas questões abertas destinadas a captar a compreensão dos docentes sobre o tema, constavam questões sobre o significado de Formação Profissional e a importância desta, bem como o tipo de formações/capacitações que estes buscam ou buscaram ao longo de sua trajetória enquanto docentes.

Após a aplicação do instrumento inicial, foi realizado um curso de formação com os professores participantes, onde 21 docentes concluíram a carga horária total de 20 horas de formação. Para compreender se houve mudança de conceito quanto a formação profissional, 
foram reaplicadas as questões sobre o entendimento dos professores sobre Formação profissional e a sua importância.

No que se refere à análise dos dados, os mesmos foram digitados e armazenados em uma planilha de dados, onde foi conferida a digitação para excluir quaisquer erros na mesma. As questões referentes ao perfil dos professores foram analisadas de forma descritiva, através da frequência de respostas e porcentagens. Já as questões abertas foram analisadas com base na Análise de Conteúdo de Bardin (2016), que consiste na pré-análise, fase de operacionalização e sistematização das ideias iniciais; na exploração do material, onde ocorre a codificação, decomposição ou enumeração; e no tratamento dos resultados, na inferência e na interpretação, visando resultados significativos e válidos para descrever a compreensão dos professores sobre formação profissional docente antes e após a participação em um curso de formação.

\section{Resultados e Discussões}

Ao analisar o perfil dos docentes dos anos finais da escola percebeu-se que a maioria são mulheres (84,6\%), com faixa etária entre 30 e 65 anos, sendo a média de idade de 44,5 anos. O tempo de formação destes profissionais variou entre 1 e 34 anos, sendo a média geral de 14 anos de formação. Os dados sobre o tempo de atuação enquanto professor variaram entre 4 a 30 anos, sendo a média de 13 anos; assim como o tempo de atuação na escola onde o estudo foi desenvolvido, variou entre 1 e 9 anos, obtendo média de 4,6 anos.

Quando questionados sobre a formação inicial os professores possuíam formação em Letras (46,1\%), História (15,4\%), Matemática (11,5\%), Pedagogia (7,8\%), Ciências (7,8\%), Artes visuais (3,8\%), Educação Física $(3,8 \%)$ e Geografia $(3,8)$. Referente à formação complementar, 65,4\% dos docentes possuíam curso de pós-graduação Lato sensu (nível Especialização), 7,7\% possuía curso de formação Stricto Sensu (nível Mestrado) e 26,9\% não possuía curso de pós-graduação ou equivalente.

De acordo com o perfil de formação dos docentes deste estudo, um levantamento realizado pelo Instituto Nacional de Estudos e Pesquisas Educacionais Anísio Teixeira (INEP) corrobora, afirmando que o nível de escolaridade do professor é predominantemente superior em todas as etapas de ensino. A formação superior vem crescendo ao longo do período, em todas as etapas da educação básica. Realizando uma média geral a âmbito nacional, 36\% dos professores são portadores de títulos de pós-graduação lato ou stricto sensu e quanto à formação continuada e a quantidade de cursos realizados em 2009 mais que dobrou em 2017 (INEP, 2018). 
Ainda entre os sujeitos, $65,4 \%$ acumulavam lotação em outra escola e a carga horária da maioria dos professores $(73,1 \%)$ foi de 20 horas na escola participante do estudo, seguido de 40 horas $(19,3 \%)$ e outras $(7,6 \%)$. Quando considerada a carga horária dos professores em outra escola tem-se a maior parte dos professores com $20 \mathrm{~h}(42,4 \%)$ de locação em outra escola, seguido de professores com 40h $(11,6 \%), 30 \mathrm{~h}(03,8 \%), 24 \mathrm{~h}(03,8 \%)$ e $10 \mathrm{~h}(03,8 \%)$ que dividem suas funções em outra instituição de ensino.

Uma análise realizada pelo Ministério da Educação em 2015, que envolveu milhares de professores e estudantes do ensino fundamental e cujos dados foram divulgados em 2018 , revela que um expressivo número de professores (66\%) trabalha 40 horas ou mais, e que $40 \%$ deles lecionavam em duas ou mais escolas (BRASIL, 2018). Ainda, outro levantamento para traçar o perfil profissional da educação básica, este realizado pelo Instituto de Pesquisa Econômica Aplicada (IPEA, 2017), destaca que existe um número minoritário, mas não desprezível, de professores atuantes em mais de uma escola, ou até mesmo fora da docência.

Tais levantamentos, problematizam sobre as dificuldades do dia a dia docente, em seu translado entre instituições e no envolvimento com cada uma delas. O documento do IPEA corrobora sobre a ideia de que uma melhor valorização salarial e a potencial redução do número de horas de atividade em sala de aula, visando aumentar o tempo de preparo das aulas, o atendimento aos alunos e as atividades de atualização e planejamento, parece ser um caminho promissor para reverter muitas das dificuldades existentes no Brasil nesta questão (IPEA, 2017).

Atrelando a percepção de professores dos anos finais do ensino fundamental no Brasil ao alto índice de professores alocados em mais de uma escola, o Relatório Nacional: Pesquisa Internacional de Ensino e Aprendizagem - TALIS 2018 (INEP, 2019) investigou professores brasileiros sobre quais as áreas de maior necessidade de investimento educacional. O estudo destacou entre os professores dos anos finais do ensino fundamental, o quesito desenvolvimento profissional de alta qualidade para os professores (95\%) e aumento salarial (93\%), como sendo as áreas que deveriam receber maior aporte.

Quando busca-se a relação entre a atuação docente em mais de uma escola e os investimentos na educação básica, percebe-se que, possivelmente, o investimento fundamental nesse cenário poderia promover mudanças positivas e significativas no ambiente escolar. Acredita-se que o professor valorizado, financeiramente e humanamente, poderá tornar-se mais efetivo no exercício da sua profissão e, assim, gerar maiores ganhos com relação ao foco principal da educação, que é o ensino-aprendizado do aluno. 


\section{Compreensão sobre Formação Profissional Docente e sua importância}

Antes da realização de um curso de formação profissional, os docentes foram questionados sobre o que entendem por Formação Profissional Docente e se a consideram importante. Os educadores foram unânimes em argumentar que a formação profissional é de suma importância e imprescindível para a "qualificação/aperfeiçoamento" e "enriquecimento do professor", e que sempre há a "necessidade de novos conhecimentos", a fim de suprir as demandas e desafios enfrentados a cada dia no ambiente escolar. Como as respostas dos docentes ilustram, abaixo:

Professor 10 - Entendo como uma ampliação no meu conhecimento, aperfeiçoamento na minha vida profissional.

Professor 19 - Entendo que formação profissional docente é a participação em cursos, palestras para atualização profissional. É muito importante, pois o professor aprende vários assuntos interessantes para sua área.

Professor 21 - Eu entendo por formação profissional docente, a minha formação (cursos, especialização). Acho importante sim, porque é necessário renovar nosso conhecimento nos atualizarmos por causa dos avanços e mudanças.

Em estudo semelhante, realizado por Lourenço et al. (2019), ressalta-se que foi possível apurar que todos os docentes atribuem grande notoriedade à sua formação continuada, apontando para a importância de manter-se sempre atualizados devido aos inúmeros desafios provenientes da docência, por meio da ampliação do saber pedagógico e da capacitação constante.

Em contrapartida, um estudo, que abordou a compreensão de gestores de educação sobre formação continuada, destaca o aperfeiçoamento como necessário à profissão, "capaz de promover a reflexão sobre teoria e prática"; e outro ponto sobre "encontro com palestrantes, a fim de abordar temas relacionados ao processo educativo" (PEDRO; PEREIRA, 2019, p. 503). Quanto a formação por meio de palestras, ressalta-se a fala de Nóvoa (2009, p. 31) quanto ao avanço da "indústria do ensino com seus produtos", no qual professores veem seu território profissional sendo ocupado por outros grupos, não necessariamente oriundos do setor educacional.

Nesse sentido, a voz dos professores é muitas vezes silenciada, sendo desconsiderada a construção dos seus saberes no contexto da sua profissão. Como também, é desvalorizado o sujeito (professor) como sujeito ativo nesse processo (PEDRO; PEREIRA, 2019). Sabe-se que a formação profissional busca o aperfeiçoamento profissional em determinada área do ensino, 
mas não se deve considerá-la um meio de formação apenas para progressão na carreira, ou então que só através de palestras o professor está se capacitando para o trabalho no ambiente escolar. Reforça-se aqui a necessidade de descobrir os anseios e dificuldades destes para planejar e executar ações que o auxiliem no seu dia a dia.

Quanto à formação profissional docente, voltada para assuntos pertinentes ao ambiente escolar em que este está inserido, Antunes et al. (2017), salientam que é necessário um olhar mais abrangente epistemologicamente, no que tange às ações e efetivas participações dos docentes neste processo. Tudo isso indica novos conceitos, propostas, fundamentados na prática reflexiva e alicerçados nas práxis estabelecida pelo docente, em cada espaço educativo (ANTUNES et al., 2017).

A docência se mostra como uma atividade complexa e desafiadora, o que exige do professor uma constante disposição para aprender, inovar, questionar e investigar sobre como e por que ensinar. $\mathrm{Na}$ sociedade atual, na qual vivemos sob constantes mudanças e infinitas incertezas, as exigências para o exercício da docência têm sido cada vez maiores, o que reforça a necessidade constante de aperfeiçoamento (PESCE; ANDRÉ, 2012).

Quando se recorre a compreensão dos participantes sobre formação profissional docente após a realização de um curso de formação para os sujeitos do estudo, curso este que faz parte da proposta de dissertação de mestrado da qual estes resultados também estão relacionados, percebe-se mudanças nos extratos das categorias da análise de conteúdo, pois os professores elencam que a formação profissional está ligada a "melhoria da prática", a "reflexão sobre a prática" bem como remetem a formação como um "processo permanente". Fica evidente a utilização da palavra "prática" nas argumentações dos professores, o que nos remete a pensar que ocorreu mudança de significado sobre o processo de formação profissional, como pode ser visto nas respostas a seguir:

Professor 03 - É o momento de estudos, reflexões sobre a prática, de troca de conhecimentos e ideias com os colegas.

Professor 05 - Entendo por formação que nos permite aperfeiçoar nossos conhecimentos e práticas pedagógicas. Considero muito importante, pois permitenos evoluir enquanto profissionais e sempre entregarmos algo melhor a nossos alunos.

Professor 13 - Entendo que é um subsídio para potencializar a prática pedagógica, sendo que estas podem ser/conter diferentes metodologias e também sobre o processo metodológico. Acredito e considero essencial, pois elas emergem do contexto para o contexto e com isso colaboram para prática e reflexão da própria prática. 
Percebe-se que os professores mudaram o foco da compreensão sobre a temática, partindo da ideia de que a necessidade de cursos de formação serve apenas para o seu aperfeiçoamento pessoal, passando a considerar os cursos de formação como uma forma de refletir e melhorar a sua práxis em sala de aula. Abordar a formação continuada de professores é falar da criação de rede de (auto)formação participada, que permita compreender a globalidade do sujeito, assumindo a formação como um processo interativo e dinâmico (NÓVOA, 2002). Colaborando com esta afirmação e também com os resultados obtidos no estudo, Imbernón (2011, p. 18) cita que:

A formação de professores deve estar ligada a tarefas de desenvolvimento curricular, planejamento de programas, melhoria da instituição educativa em geral, e nelas implicar-se, tratando de resolver situações problemáticas gerais ou específicas relacionadas ao ensino em seu contexto.

Quanto a identificação dos professores sobre a necessidade de reflexão da prática pedagógica, Nóvoa (1995) argumenta que a "formação se constrói através de um trabalho de reflexão crítica sobre as práticas e de (re)construção permanente de uma identidade pessoal, por isso é tão importante investir na pessoa e dar estatuto ao saber da experiência”. O autor (NÓVOA, 2001), reforça, ainda, que a formação de professores necessita de novos rumos, carece alicerçar-se numa reflexão na prática sobre a prática, através de dinâmicas de investigação-ação e de investigação-formação, valorizando os saberes de que os professores são portadores e intimamente ligados com as práticas educativas.

Concorda-se com Bonfim-Silva e Carmo (2020), ao tratarem da formação e do saber de professores da educação básica, onde estes professores em sua prática em sala de aula recebem diversas influências, sejam elas pessoais, sociais e/ou coletivas. E ainda, entendem que, se o professor atua de forma reflexiva, o tempo poderá contribuir significativamente para o "ser professor" por meio do desenvolvimento, da reconfiguração e do aperfeiçoamento de seu saber.

Percebe-se, ao realizar a comparação pré e pós curso de formação, que ao realizar o curso estes profissionais passaram a compreender que a sua formação carece de modelos de formação reflexiva. Tal modelo vem se aprofundando, tanto em questões teóricas como orientações para a prática. Este surgiu, para a formação docente, como possibilidade de refletir a prática e suas ações em sala de aula (SANTOS; CAVALCANTE, 2018). Dentre os estudiosos dessa área, podemos citar: Schön (2000), Pimenta (2008) e Imbernón (2011).

Buscando associar o pensamento dos participantes à ações realizadas no território brasileiro, orientações para formar "professor reflexivo" vêm sendo bastante referendadas nos 
cursos de formação continuada no município de Maceió (SANTOS; CAVALCANTE, 2018), que se fundamentam nas propostas de formação de professores ofertadas em nível nacional pelo Ministério da Educação e Cultura (BRASIL, 2011). O termo "professor reflexivo" não é muito novo na educação, como afirma Pimenta (2008). A expressão tomou conta do cenário educacional, confundindo a reflexão enquanto adjetivo, como atributo próprio de um ser humano, com um movimento teórico de compreensão do trabalho docente (PIMENTA, 2008).

Os participantes foram questionados sobre o tipo de atividades formativas frequentaram nos últimos 02 anos, bem como por qual instituição essas ações foram propostas. Ao analisálas, surgiram algumas categorias de respostas, como: ações propostas pela mantenedora (rede de ensino municipal); ações propostas pelas Universidades da cidade; cursos online/seminários/palestras; entre outros. Foi possível identificar que a grande menção foi a atividades propostas pela entidade mantenedora $(42,3 \%)$, seguido de cursos online $(38,6 \%)$, estes buscando assuntos pertinentes a área em que cada professor é atuante, eventos realizados pelas universidades alocadas na cidade $(3,8 \%)$, leituras $(3,8 \%)$ e ainda alguns responderam não ter tempo de participar de atividades formativas $(11,5 \%)$.

Acredita-se, segundo as informações obtidas, que estes docentes estão refletindo e preocupando-se de acordo com a demanda social que surge na escola, como também, extremamente preocupados com sua capacitação para o enfrentamento positivo de tais demandas. Concorda-se com Silva e Darsie (2019), quando os autores trazem que a escola e os professores inseridos nesse contexto requerem um novo olhar e novas ações que demandam muito mais participação social, ética, moral e científica, em um envolvimento concreto, refletindo sobre essas novas demandas, a fim que a formação contribua com a preparação desse profissional para os desafios educativos (SILVA; DARSIE, 2019).

Corroborando com este estudo, no sentido de que uma formação centrada no ambiente escolar pode provocar um processo de melhoria permanente, Mucharreira (2017, p.106) nos traz que, "perspectivando iniciativas reflexivas e formativas que possibilitem aos professores a melhoria das suas práticas, elevando a qualidade do ensino e consequentemente das aprendizagens efetivas e duradouras nos alunos". Este desenvolvimento docente, pode surgir em consequência de uma formação contextualizada, e possibilitar o alcance de uma aprendizagem coletiva de toda a estrutura organizacional (BOLÍVAR, 1997; BARROSO, 1997).

Os docentes também foram questionados sobre qual seria a sua avaliação sobre os cursos nos quais estes participaram nos últimos anos e de que forma estes contribuíram para a sua 
prática docente. A maioria afirma que as ações foram de "grande valia para sua prática docente", e que serviram para possibilitar "a reflexão de suas ações" no ambiente escolar, o que corrobora com a questão do professor reflexivo, abordada anteriormente. Destacam-se abaixo algumas respostas:

Professor 02 - Todos foram de grande valia para a minha prática, uma vez que cada um possibilitou novas experiências, contatos e vivências.

Professor 06 - Alguns são "coisas" que a gente já sabe, mas sempre tem algo que colabora para nosso aprimoramento mesmo sendo um tema batido. Tudo vem a acrescentar para nossa prática, melhorando nossa forma de pensar e atuar.

Professor 19 - Positivo, pois toda a formação é válida para buscarmos um melhor desempenho profissional.

Porém, dentre as respostas, sete professores elencaram alguns aspectos negativos nas últimas formações que participaram, tais como: necessidade de utilização de temas mais profundos e conectados com a prática docente; disponibilidade de tempo para participar das formações, pois a docência os sobrecarrega muito; as temáticas já saturadas, onde não surgem novas questões a serem debatidas ou outras metodologias para abordar os conteúdos. Algumas das respostas destes professores ressaltam a necessidade de cursos de formação pensados na realidade escolar, mas de alguma forma, todos consideram de extrema necessidade cursos de formação continuada, apesar de repetitivos ainda há a possibilidade de reflexão sobre a sua prática.

Professor 03 - A partir de uma avaliação pontual, penso que muito pouco contribuíram. Sempre concluo que poderiam (os cursos) ser mais profundos e conectados com a vida real.

Professor 17 - Alguns relevantes, alguns repetidos... Mesmo assim é possível acrescentar algo na prática docente.

Professor 21 - Ainda não encontrei um curso de formação continuada que contribuísse com minha formação, que deve ser diária.

Ao analisar alguns pontos levantados pelos docentes quanto à participação em cursos onde não houveram aprendizados significativos, concorda-se com Costa (2019), quando este trata sobre as falhas nos programas de formação de professores. Tais falhas têm levado ao desinteresse e reações de indiferença por parte dos docentes, por perceberem que certas atividades que prometem ser de formação, nem sempre, contribuem para seu desenvolvimento profissional (COSTA, 2019).

Corroborando com a discussão sobre os achados, Lourenço et al. (2019) também constatou que o modo como as formações vêm sendo oferecidas não representam contribuições 
expressivas às práticas em ambiente escolar, devido a incongruências na maneira como são realizadas. Segundo os autores, estas apresentam um distanciamento entre teoria e prática, gerando assim pouca aplicabilidade dos conteúdos das ações oferecidas na atuação do docente. Ainda, complementa-se que, assim como os dizeres de Nóvoa (2001), é importante dar voz aos professores, trazer à tona o que eles sabem e colocar esses saberes em pauta, considerando os docentes como protagonistas do próprio processo de conhecimento, e não objetos dele (LOURENÇO et al., 2019).

Segundo Morin (2008), a formação de professores precisa ser pensada de modo que possibilite a estes uma reflexão acerca de suas práticas, trazendo para a discussão uma "nova" maneira de fazer ciência, à luz de um novo paradigma, onde o objeto se comunique como sujeito. O que consequentemente implicará em contribuições para sua prática pedagógica em sala de aula (SILVA; DARSIE, 2019).

Outra questão importante investigada no estudo diz respeito às principais motivações que levaram os docentes a participar das ações formativas. Foi possível verificar que a maioria dos docentes $(71,5 \%)$ frequentavam cursos de formação tendo como a principal motivação a busca pessoal por aperfeiçoamento. Os demais docentes afirmaram participar das ações motivados por convocação $(4,5 \%)$ da própria mantenedora, como também outros destacam ser motivados por ambas razões, convocação e busca pessoal por aperfeiçoamento (24\%).

A formação de professores vem ao longo dos tempos se efetivando como uma necessidade constante de ações, distantes de propostas pontuais, ou mesmo de momentos marcados por programas e ações distantes das realidades escolares e de educadores. Muito além das necessidades de professores e de alunos, impõe-se uma concepção de formação que seja contínua; uma educação ao longo da vida, com possibilidade de constantes aprendizagens (ANTUNES et al., 2017). Colaborando com os achados deste estudo, Imbernón (2011, p. 342) nos diz que em um cenário ideal, a "formação docente deveria girar sobre o eixo da relação entre teoria e prática, além de oferecer uma visão holística e crítica das capacitações, sejam de formação docente ou na motivação do atuar na prática pedagógica".

Forte e Assumpção Flores (2013), destacam o pensamento de professores oriundos de Portugal, com relação a motivações para a realização de atividades de aperfeiçoamento ou o engajamento em oportunidades de formação profissional. Estes professores valorizaram ações mais emancipatórias e práticas, como desenvolver-se gerando uma nova proposta para o ensino e a vontade de ampliar sua visão pedagógica, e ainda em menor número, são citados projetos de pesquisa com colegas. Percebeu-se uma compreensão mais ampla sobre a formação de 
professores em Portugal, mas também a ampliação da mesma com relação aos participantes do estudo, pois ao ficarem expostos pelos participantes, as principais dificuldades nos cursos em que participaram, também estão refletindo sobre o tipo de ação que seriam mais efetivas ao seu contexto escolar.

Uma possibilidade para motivar os professores quanto a formação profissional, seria considerar, além de uma abordagem sobre como trabalhar os conhecimentos científicos da disciplina de estudo e utilizar as ferramentas e metodologias de ensino, relacionar estes aos saberes docentes desses professores. Conforme Tardif (2014, p. 36), "pode-se definir o saber docente como um saber plural, formado pela amálgama, mais ou menos coerente, de saberes oriundos da formação profissional e de saberes disciplinares, curriculares e experienciais". Aliar os conteúdos que são obrigatórios, com as práticas de formação que considerem os contextos escolares, pode ser uma motivação para que os professores busquem por maior aperfeiçoamento.

Outro ponto que pode contribuir para a motivação de professores no processo de formação profissional é quanto a propostas bem-sucedidas, no sentido de realmente evidenciar e auxiliar os mesmos na solução de problemas oriundos da realidade a qual estão inseridos. Quando os professores encaram essas propostas como fontes de inspiração, simultaneamente, estas são entendidas como elementos necessários ao próprio aperfeiçoamento pessoal e profissional (HERDEIRO; COSTA e SILVA, 2014).

Ao final dos questionamentos, os participantes responderam se consideravam que as atividades de formação profissional contribuíram para a sua atuação docente. Os mesmos foram unânimes em afirmar que as ações contribuem para sua formação, pois através delas é possível repensar suas estratégias de ensino, bem como buscar novas metodologias de ensino para auxiliar na aprendizagem de seus alunos. $\mathrm{O}$ discurso dos professores é enfático quanto à necessidade de estar em "constante aperfeiçoamento", visando a "melhoria do processo de ensino-aprendizagem" em sala de aula e também da própria "satisfação quanto educadores".

Professor 03 - Sim. Quanto mais útil me torno para os alunos, mais sentido acho em viver e estar fazendo o que faço.

Professor 05 - Com certeza. A prática profissional enriquece o dia a dia e norteia o professor no sentido de buscar atualização em determinadas práticas. Professor 20 - Sim, acredito em uma troca, assim como o que aprendo nas formações contribui com a sala de aula o que realizo na minha prática influencia na minha formação. 
Corroborando com o pensamento dos docentes sobre a necessidade constante de aperfeiçoamento, considera-se oportuna a preocupação com diferentes abordagens metodológicas no que concerne às propostas de formação: há que se estabelecer um modelo de construção contínua, um modelo de aprendizagem social, com propostas relacionais de vivências dentro do ambiente de trabalho (ANTUNES; PLASZEWSKI, 2018).

A formação docente não deve estar simplesmente associada à transmissão de conteúdos nos cursos de formação ou mesmo esperar que somente com as experiências do dia a dia o indivíduo se tornará um bom profissional. A formação de professores requer conhecimentos unificados e que insira o professor como pessoa em busca de uma identidade profissional (DINIZ-PEREIRA, 2015). Nesse sentido, deve-se também admitir que a formação passe pela experiência, pela inovação e pelo ensaio de novos modos de trabalho pedagógico. Esta requer ainda, a participação dos professores em processos reflexivos e não somente informativos (SILVEIRA, 2006).

Ainda sob esta perspectiva, Nóvoa (2007) aborda a questão do social e do educativo, destacando que são os próprios professores que têm de encontrar os caminhos, as soluções e assumir as decisões. Isso está dentro do quadro da autonomia da profissão docente e, por isso, destaca que a única maneira de estar na educação é numa perspectiva constante de interrogação, de dúvida, de procura e construção dos melhores caminhos para cada momento.

Sabe-se que muitas vezes, caminhar e fazer o próprio caminho é uma situação inusitada e, por vezes, complexa no ambiente escolar. Porém, contar com o apoio das instituições de ensino superior (IES) através de projetos de pesquisadores com embasamento científico para acompanhar e guiar tal processo formativo, pode ser uma alternativa em potencial. Destaca-se também, a necessidade de um processo formativo contínuo que mobilize os professores para um trabalho coletivo e interdisciplinar, deslocando a perspectiva de formação centrada nos aspectos instrumentais para uma perspectiva que considere o professor enquanto agente de si mesmo, capaz de analisar e refletir, criticamente, seus saberes e práticas na articulação com o contexto em que atua (PAES; PEREIRA, 2017).

Nesse sentido, uma possibilidade é a formação de professores centrada na escola como foi relatado de forma sucinta na discussão dos resultados. Através da parceria entre ensino e pesquisa, no que diz respeito às parcerias entre IES e escolas públicas de ensino básico. A partir das manifestações obtidas, vê-se o real interesse, as necessidades e as principais motivações dos professores pela constante atualização profissional. A busca pelo aperfeiçoamento profissional dos professores é por vezes pensada para auxiliar nos diversos processos 
formativos da própria comunidade escolar, e as IES podem colaborar nesse contexto através da pesquisa e implementação de ações formativas.

\section{Considerações Finais}

Considerando o perfil dos docentes, um fato que chamou atenção no estudo é que mais da metade dos participantes possui lotação em outra escola, o que acarreta um maior tempo de planejamento, pois deve-se levar em conta as diferentes peculiaridades de cada contexto escolar. Ao mesmo tempo, ficou evidente a importância da formação profissional por parte dos docentes, mas que esta esteja intimamente ligada ao contexto educacional onde estes estão inseridos, pois muitos foram os relatos de assuntos repetitivos, fora de contexto e de caráter extremamente teórico, sem relação com a prática em ambiente escolar. Apesar deste posicionamento, os professores argumentam que de alguma forma, por mínima que seja, os cursos sempre trazem alguma ideia válida para si próprios e o desenvolvimento de suas atividades.

Quanto a compreensão sobre formação profissional docente antes e após o curso desenvolvido, percebeu-se uma mudança importante, onde os professores passaram a enxergam a formação como uma reflexão sobre a prática e, não apenas como uma forma de aperfeiçoamento ou forma de progressão na carreira. Destacando, assim, que tal reflexão foi capaz de auxiliá-los em um melhor preparo para as ações do dia a dia em sala de aula.

Nesse sentido, ressalta-se a necessidade do diagnóstico de compreensões sobre a importância e as necessidades formativas de professores, para que os cursos de formação, oficinas e demais ações pensadas para o aperfeiçoamento profissional, caminhem em consonância com a realidade educacional onde o professor está inserido. Se faz necessário, ainda, pensar na formação de professores como uma ação planejada de forma que consiga unir expressivamente os conteúdos teóricos, com as práticas necessárias para, assim, tornar efetivo o processo de ensino-aprendizagem no contexto escolar.

\section{REFERÊNCIAS}

ANTUNES, Denise Dalpiaz; PLASZEWSKI, Helenara. O ser professor em contínua construção. Revista Educação. Porto Alegre, v. 41, n. 1, p. 30-40, jan.-abr. 2018. 
ANTUNES, Denise Dalpiaz; et al. Formação Continuada de Professores no Locus Escolar. In: ANTUNES, Denise Dalpiaz; PLASZEWSKI, Helenara. Educação continuada: um paradigma em diferentes ações, distintas experiências e significativos contextos. Porto Alegre: Evangraf, 2017.

BARDIN, Laurence. Análise de conteúdo. $3^{\mathrm{a}}$ reimp. da $1^{\mathrm{a}}$ ed. São Paulo: Edições, v. 70, 2016.

BARROSO, Joao. Formação, projecto e desenvolvimento organizacional. In: CANÁRIO, Rui (Org.). Formação e situações de trabalho. Porto: Porto Editora, p. 61-78, 1997.

BOLÍVAR, António. A escola como organização que aprende. In: CANÁRIO, Rui (Org.). Formação e situações de trabalho. Porto: Porto, p. 79-100, 1997.

BONFIM-SILVA, Venâncio; CARMO, Edinaldo Medeiros. Saberes experienciais: reflexões sobre a prática pedagógica no ensino de ciências e biologia. Práxis Educacional, [S.1.], v. 16, n. 38, p. 421-440, jan. 2020. ISSN 2178-2679. Disponível em:

<http://periodicos2.uesb.br/index.php/praxis/article/view/6018>. Acesso em: 12 mar. 2020. doi: $\underline{\text { https://doi.org/10.22481/praxisedu.v16i38.6018. }}$.

BRASIL, Ministério da Educação. Plano Nacional de Educação - PNE. Brasília, DF: INEP 2011.

BRASIL. Instituto Nacional de Estudos e Pesquisas Educacionais Anísio Teixeira (INEP). Censo escolar da educação básica 2018. Brasília: INEP. 2019.

COSTA, Jandira Gomes da. A formação continuada do docente e as dificuldades na prática pedagógica. Revista Psicologia e Saberes. V.8, N.10 2019, p. 278-287.

DINIZ-PEREIRA, Julio Emílio. Formação De Professores, Trabalho E Saberes Docentes. Trabalho \& Educação, Belo Horizonte, v.24, n.3, p.143-152, set-dez, 2015.

FONTANA, Maire Josiane; FÁVERO, Altair Alberto. Professor reflexivo: uma integração entre teoria e prática. Revista de Educação do IDEAU, v. 8, n. 17, 2013.

FORTE, Ana Maria; FLORES, Maria Assunção. Colaboração docente e desenvolvimento profissional no local de trabalho: um estudo de professores de português, European Journal of Teacher Education, 2014. 37: 1, 91-105, DOI: 10.1080 / 02619768.2013.763791.

GALINDO, Camila José; DO CARMO INFORSATO, Edson. Formação continuada de professores: impasses, contextos e perspectivas. Revista on line de Política e Gestão Educacional, p. 463-477, 2016.

GIL, Antonio Carlos. Como elaborar projetos de pesquisa. 5 ed. São Paulo: Atlas, 2010.

GOMES, Rita de Cássia Medeiros. A formação dos professores no contexto atual. Revista de Educação, v. 14, n. 18, 2015. 
HERDEIRO, Rosalinda; COSTA e SILVA, Ana Maria. As políticas educativas e a motivação dos professores para o trabalho docente. In: Congresso formação e trabalho docente na sociedade da aprendizagem. Centro de Investigação em Estudos da Criança (CIEC), 2014. p. 1390-1401.

IMBERNÓN, Francisco. Formação docente e profissional: formar-se para a mudança e a incerteza. Traduzido por Silvana Cobucci Leite. São Paulo: Cortez, 2011.

INEP. Instituto Nacional de Estudos e Pesquisas Educacionais Anísio Teixeira. Relatório nacional: pesquisa internacional sobre ensino e aprendizagem: Talis 2018: primeira parte. Brasília: Inep, 2019. Disponível em:

http://download.inep.gov.br/acoes_internacionais/pesquisa_talis/resultados/2018/relatorio_na cional_talis2018.pdf

INEP. Perfil do professor da educação básica / Maria Regina Viveiros de Carvalho. -

Brasília, DF: Instituto Nacional de Estudos e Pesquisas Educacionais Anísio Teixeira, 2018.

Disponível em: http://portal.inep.gov.br/informacao-da-publicacao/-

lasset_publisher/6JYIsGMAMkW1/document/id/1473981 Acesso em: 26/dez/2019.

IPEA - Instituto de Pesquisa Econômica Aplicada. Textos para Discussão. Professores da educação básica no Brasil: condições de vida, inserção no mercado de trabalho e remuneração, Brasília, n. 2304, 2017.

LEITÃO, Álvaro; ALARCÃO, Isabel. Para uma nova cultura profissional: uma abordagem da complexidade na formação inicial de professores do $1^{\circ} \mathrm{CEB}$. Revista Portuguesa de Educação, Braga, v. 19, n. 2, p. 51-84, 2006.

LOURENÇO, Rayana Silveira Souza Longhin; et al. Formação continuada em serviço: relações entre seus aspectos fundamentais e as práticas instituídas. Práxis Educacional, [S.l.], v. 15, n. 32, p. 481-498, maio 2019. ISSN 2178-2679. Disponível em:

<http://periodicos2.uesb.br/index.php/praxis/article/view/5065>. Acesso em: 24 mar. 2020. doi: https://doi.org/10.22481/praxis.v15i32.5065.

MORIN, Edgar. Ciência com Consciência. Tradução: Maria D. Alexandre e Maria Alice Sampaio Dória. 11. Ed. Rio de Janeiro: Bertrand Brasil. 2008. 350p.

MUCHARREIRA, Pedro Ribeiro. O papel da formação contínua, centrada na escola, na (re)construção do projeto educativo e no desenvolvimento profissional docente: um estudo de caso. Lisboa: Instituto de Educação da Universidade de Lisboa, 2017. https://repositorio.ul.pt/bitstream/10451/28886/1/ulsd730791_td_Pedro_Mucharreira.pdf

NÓVOA, Antonio Sampaio da. Formação continuada de professores: realidade e perspectivas. Aveiro: Universidade de Aveiro, 2001.

NÓVOA, Antonio Sampaio da. Formação de professores e profissão docente. In. NÓVOA, A. S. (Coord). Os professores e a sua formação. 2. Ed. Lisboa: Dom Quixote, 1995. p. 15-33.

NÓVOA, Antonio Sampaio da. Formação de Professores e Trabalho Pedagógico. Lisboa: Educa, 2002. 
NÓVOA, Antonio Sampaio da. História de vida: perspectivas metodológicas. In: NÓVOA, A. S. (org.). Vida de Professores. $2^{\mathrm{a}}$ ed. Porto: Porto Editora. 2007.

NÓVOA, Antonio Sampaio da. Professores: imagens do futuro presente. Lisboa, Educa, p. 241, 2009.

NÓVOA, Antonio Sampaio da. Firmar a posição como professor, afirmar a profissão docente. Cadernos de Pesquisa, v.47 n.166 p.1106-1133 out./dez. 2017.

NÓVOA, Antonio Sampaio da. Entre a formação e a profissão: ensaio sobre o modo como nos tornamos professores. Currículo sem Fronteiras, v. 19, n. 1, p. 198-208, jan./abr. 2019.

PAEZ, Fabiana Martinello; PEREIRA, Antonio Serafim. Formação continuada: a visão dos professores de um curso de graduação tecnológica. Acta Scientiarum. Education, v. 39, n. 1, p. 567-575, 2017.

PEDRO, Lessandra Mariléia Silvano; PEREIRA, Antonio Serafim. Formação continuada de professores: concepção dos gestores de dois sistemas municipais de ensino catarinenses. Práxis Educacional, [S.1.], v. 15, n. 36, p. 494-513, dez. 2019. ISSN 2178 2679. Disponível em: 〈http://periodicos2.uesb.br/index.php/praxis/article/view/5902〉. Acesso em: 16 mar. 2020. doi: https://doi.org/10.22481/praxisedu.v15i36.5902.

DE PESCE, Marly Krüger; DE ANDRÉ, Marli Elisa Dalmazo Afonso. Formação do professor pesquisador na perspectiva do professor formador. Formação Docente-Revista Brasileira de Pesquisa sobre Formação de Professores, v. 4, n. 7, p. 39-50, 2012.

PIMENTA, Selma Garrido. Professor reflexivo: Construindo uma crítica. In Ghedin, Evandro (Org.), Professor reflexivo no Brasil: Gênese e crítica de um conceito. São Paulo: Cortez, 2008.

SANTOS, Marta Maria Minervino dos; CAVALCANTE, Marta Auxiliadora da Silva. A formação continuada de professores e seus reflexos no ensino da leitura nos anos iniciais. Anais... do XIV Colóquio Internacional de Psicologia e Educação, p. 37-49, 2019.

SCHÖN, Donald. Educando o profissional reflexivo: Um novo design para o ensino e a aprendizagem. Porto Alegre: Artmed, 2000.

SILVA, Lucenildo Elias da; DARSIE, Marta Maria Pontin. A formação continuada em mato grosso: algumas aproximações conceituais e a política de formação de professores da rede estadual. Revista Panorâmica - V. 27 - Jan./Jun. 2019, p.11-24.

SILVEIRA, Daniel. Formação Docente: Aspectos pessoais, profissionais e institucionais. Anais... Seminário Nacional de Filosofia e Educação: Confluências, Santa Maria, RS, 2006.

SOUZA, Régis Luíz Lima de. Formação continuada dos professores e professoras do município de Barueri: compreendendo para poder atuar. 2007. Tese de Doutorado. Universidade de São Paulo. 
TARDIF, Maurice. Saberes docentes e formação profissional. 17. Ed. Petrópolis, RJ:

Vozes, 2014.

\section{SOBRE AS AUTORAS:}

\section{Renata Godinho Soares}

Mestranda no Programa de Pós-Graduação em Educação em Ciências: Química da Vida e Saúde e especialista em Atividade Física e Saúde pela Universidade Federal do Pampa (UNIPAMPA) - Campus Uruguaiana. Pesquisadora no Grupo de Estudos e Pesquisa em Estágio e Formação de Professores (GEPEF). Licenciada em Educação Física pela Universidade da Região da Campanha - Campus Alegrete. Tem experiência na área de Educação Física, com ênfase em esportes, recreação e saúde; Processos de Ensino-Aprendizagem utilizando Metodologias Ativas; e Formação de Professores. E-mail: renatasg2006@yahoo.com.br iD http://orcid.org/0000-0002-2386-2020

\section{Jaqueline Copetti}

Graduação em Educação Física pela Universidade Federal de Santa Maria (UFSM), mestrado em Educação Física pela Universidade Federal de Pelotas (UFPel)e doutorado em Educação em Ciências: Química da Vida e Saúde pela Universidade Federal de Santa Maria (UFSM). Atualmente é Professora Adjunta da Universidade Federal do Pampa (UNIPAMPA), Campus Uruguaiana/RS, atuando no Curso de Licenciatura em Educação Física e Docente Permanente do Programa de Pós-graduação em Educação em Ciências: Química da Vida e Saúde. Líder do Grupo de Estudos e Pesquisa em Estágio e Formação de Professores (GEPEF). E-mail: jaqueline.copetti@gmail.com

iD http://orcid.org/0000-0003-4838-1810 